Mid-American Review of Sociology

4. This discussion of aging in the U.S.S.R. is taken in large part from Walter C. McKain, "The Aged in the USSR." Pp. 151-165 in D.O. Cowgill and L.D. Holmes, Aging and Modernization. New York: Appleton-Century-Crofts, 1972

\section{PARTICIPANT OBSERVATION IN A \\ MULTIPLE-METHODS STUDY OF A \\ RETIREMENT COMMUNITY: A RESEARCH NARRATIVE ${ }^{1}$}

\author{
Victor W. Marshall \\ University of Toronto
}

Mid-American Review of Sociology, 1981, Vol. VI, No. 2:29-44

In social science research, choice of methodology is constrained by the real or perceived biases of funding agencies' conception of what will persuade audiences who may or may not use the results of the study for good or evil, and the convictions of investigators as to what constitutes valid data. For most audiences in sociology and social gerontology, and I suspect for most funding agencies, precisely defined and measured variables and numerically tested hypothesis constitute the language of persuasion. As Herbert Blumer (1969:37) argues:

... most research inquiry ... is not designed to develop a close and reasonably full familiarity with the area of life under study. There is no demand on the research scholar to do a lot of free exploration in the area, getting close to the people ... being party to their conversations and watching their life as it flows along. In place of such exploration and flexible pursuit of intimate contact with what is going on, reliance is put on starting with a theory or model, posing a problem in terms of the model, setting a hypothesis with regard to the problem, outlining a mode of inquiry to test that hypothesis, using standardized instruments to get precise data, and so forth....

Blumer suggests that it is difficult to obtain funding for any research that does not conform to the hypothesis-testing model. I sense that this is correct, for the pages of our major sociology and gerontology journals suggest either that it is hard to fund such research or hard to publish it. ${ }^{2}$ 
My own problem has been twofold. First, in my research I wish to develop evidence which I find believable: I want to find out, with confidence, what is really going on. That is not a very large problem: to live in a field setting and to survive provides a great deal of evidence as to what is going on there. The second problem is to convince someone who was not there that my interpretation of what is going on is useful or reasonable. The difficulty of the latter as contrasted with the ease of the former was stressed to me by Bob Scott, my doctoral supervisor at Princeton, who persuaded me that I should have a survey component as well as a participant observation component. I was also persuaded by my director of graduate studies, who told me "In this department students can do whatever they want; but you should remember that not everyone can be an Erving Goffman." This warning, as has been noted by Heeren and Poss (1971), is often given to graduate students who contemplate serious use of field methods. No wonder qualitative methods are thought by many to be lacking in rigor: Goffman's brilliance lies not in rigor or systematic analysis, but in insight (Glaser and Strauss, 1967). My own research career has convinced me that participant observation, when done rigorously (and I have not always been rigorous as I try to teach students to be) can yield data as valid or more valid than the survey approach, and certainly more generalizable than data gathered through experimental techniques. $^{3}$ I am not, however, antagonistic to traditional methods, but rather argue for the use of multiple methods in any investigation, where at all possible (Denzin, 1970; Webb et al., 1966: 137-144).

By participant observation I refer not to a specific method, but to a "blend of methods and techniques that is characteristically employed in studies of social situations or complex social organizations of all sorts" (McCall and Simmons, 1969:3). It is often called "field work" and includes varieties of role relationships varying in degree of participation and observation (Junker, 1960: Ch. 3). Its distinguishing characteristics are first-hand contact with the world under study and the gathering of significant proportions of the data in qualitative form (Lofland, 1971); and where done well, it involves a continuous moving back and forth between data collection and analysis, with the latter guiding strategies for the former (Glaser and Strauss, 1967; Lofland, 1971; Schatzman and Strauss, 1973: 117). This on-going interplay between data collection and analysis stems partly at least from the frequent use of participant observation in situations where the investigator has little clarity about the scene being studied, and no clearly articulated theory to test (Becker, 1958).

Participant observation or field methods have been less frequently used in social gerontology than in sociology in general, which has focused inordinately on quantification, the scaling of variables (varieties of life satisfaction and morale measures especially), and multivariate analysis (as I argue in Marshall and Tindale, 1979). Imperialism about methodological approaches is the last thing we need; but recent years have seen some excellent examples of gerontological scholarship employing field methods alone (Chappell, 1978; Gubrium, 1975; Hochschild, 1973; Kiefer, 1974; Matthews, 1975, 1979; Myerhoff, 1978; Ross, 1977; Stephens, 1976; Tindale, 1980) or in conjunction with survey research methods (Bengston, Cuellar and Ragan, 1977); and I would like to praise and support this trend. Field work or participant observation studies should not require justification: the depth of understanding and new insight which they have yielded are perhaps justification enough. What I wish to do, however, is to draw on some of my own research experience to argue for the benefits of joint use of field-work and other methods in gerontological research.

I will hang my remarks on research I conducted for my doctoral dissertation, begun over thirteen years ago. This project yielded several empirical reports and informed my thinking in some of my theoretical writings. Since I cannot assume that this work is well known, let me briefly say that I set out, in 1968, to examine the implication, for people who were old, of the fact that increasing age brings nearness to death. I wanted to try to understand the way in which the recognition that death draws near affected the lives of the aged.

The methodology I used for this research included: 
1. Participant observation in a retirement village and to a lesser extent in a nursing home/home for the aged. Observation was carried on over a period of one and a half years, though not continuously.

2. Focused interviews with strategic individuals, as this seemed desirable in the field work situation.

3. Gathering as much archival data as possible from administration records, and any additional material which residents or administrators would provide.

4. Systematic interviews with a sample of residents in the retirement village. Besides about 40 interviews in the pilot stages, the main survey data base consisted of three interviews of one hour duration with each of 69 residents of the retirement village.

In the analysis, I sought to address as many issues as possible through as many data sources as possible. I therefore use survey and participant observation and archival data in most of the reports of this research. I should add that I had not originally intended to conduct formal interviews. My committee forced me to do so. It is also worth noting that I constructed my formal interview schedules while in the field, delaying the necessary crystallization of questions as much as possible. Thus, I did not draw a sample for the formal interviews until most residents of the retirement community knew me, or at least knew of me, from the participant observation. I did not complete the second interview schedule until $I$ was in the midst of doing the first interviews; and I similarly prepared the third interview schedule while conducting the second wave. As a last point about the methodology, the data-gathering was accomplished entirely without any financial assistance.

Let us focus on some of the contributions which participant observation can make to a multiple-method approach in gerontology.

\section{ENHANCING COMPLETENESS OF DATA}

A great deal of the everyday lives of older people has little chance of becoming recorded in a survey. In my own case, I diverted attention away from my initial research proposal in order to concentrate on an issue which became very important during the period of my field work. While I continued to gather data through observation and interviews, concerning the social psychology of aging and dying (my initial and official focus), I was able to gather much data about the conflict between residents and administration of the retirement village over escalation in the monthly rental fees and charges of inept and even unethical management.

In this instance, which I have reported in two papers (1973 and 1975a), residents attempted to co-opt me as an apologist in their struggles with management, and they provided a wealth of information concerning their version of the dispute. The administration acceded to my requests for its version of the problem, and opened many of its records to me. Incidently, invocation of the norm of scientific neutrality helped me with both administration and residents in this case. The data led to what I personally consider to be the most interesting paper from my doctoral research; and my point is that had I conducted my research through a survey methodology alone, I would not have had the flexibility to seize this opportunity. Moreover, these data on the financial disputes between residents and management were in fact relevant to my social psychological concerns about the impact of impending death, because the dilemma a resident faced with escalating rental costs related directly to real and anticipated life expectancy.

This came through most clearly perhaps with respect to one crusty woman who refused on principle to let me ever formally interview her, but who often joined me in the snack bar and told me anything I wanted to know. One day she forgot her sweater in the snack bar, and when I returned it to her apartment she provided me with a quotation which made me say, "whoopee": because it expressed so well the financial dilemmas of so many residents. She was opening her mail, and 
she said to me, "I just got my bank statement, and it isn't too high. I'll have to be careful from now on. If you knew how long you had (to live) you could figure it out to the cent. But you can't" (Marshall, 1973).

It is true but trite to say that adding a participant observation component to a survey research study enhances completeness of data, simply because you end up with more data. Beyond that, however, the main contribution is in gap-filling, in providing data not likely to be gathered through a survey alone. Observations of who used public places, and with whom, provided me with data as to which residents were isolated and which were relatively closely knit into the life of the community. Seeing and hearing the reactions of ambulatory residents to those in wheelchairs probably gave me more valid data than answers to questions about people's attitudes to the use of wheelchairs.

\section{QUALITATIVE DATA AS A SOURCE OF THEORETICAL IDEAS}

The conservative argument for the use of participant observation in tandem with other methods is to suggest that a pilot study using qualitative methods can suggest good ideas for subsequent survey research (e.g., Barton and Lazarzfeld, 1955). This is an important use of the participant observation, but need not obviate continuing the participant observation phase throughout the entire data-gathering period during which surveys are being conducted. Even if ideas are not generated from participant observation in time for the inclusion of survey items to test them directly, such ideas often lead to new research questions, and these can be tested just as respectably as is the case with any secondary analysis of survey data gathered for other purposes. I would like, however, to recount one example from my research in which the research idea did in fact come in time to allow item-construction for a survey test.

Not knowing very precisely what I was interested in, I followed the standard advice to people in the field: force yourself to write everything down as concretely as possible. When invited to a resident's apartment for tea, I would try to note concrete details, such as the kinds of pictures on the wall, the names of magazines lying about, and the like. I also tried to identify what kind of books were on shelves (I had a folknotion that old people would read a lot of religious books). Only when going over field notes after a brief time in the field did I discover a pattern: many people had biographies and autobiographies on their shelves. I wrote in my field notes: "I must investigate: whether biographies are often read by aging personswhy they are liked. Relationship to typologies of death-anticipation, etc."

In fact, there was virtually nothing in the research literature of gerontology about reading preferences-only one article suggesting that older people like to read biographies in order to punish themselves by stressing the contrast between their own lives and those of successful subjects of biography. That did not make much sense to me, and I continued to be intrigued by what might be a pattern. I was even more careful to note reading preferences in my continuing field work. I also visited the library in the retirement village, and found biography was one of the only four main sections of the collection (the others being mysteries, travel, and miscellaneous). I therefore determined to check out reading patterns through the formal interviews. This could have been done through qualitative data from participant observation, but to spend so much time on that little question would have been silly. It was easier to ask people what kind of reading was their favorite. I found, in fact, that people who listed biography and autobiography as a favorite kind of reading were more intensely involved in self-focused reminiscence in a life review process (Marshall, 1974, 1975c). While this is not a key aspect of life review theory, it is something I find interesting, and it is not without practical application, at least for those directing library services to the aged population; and I have never seen another reference to this point.

More important for my developing analysis, this little finding concerning the reading of biography gave me a central metaphor (and it is indeed a metaphor) for a major part of my theorizing: I came to see older people as, in a metaphorical sense, seeing themselves in the last chapters of their biography. They 
re-write their biography in a reminiscence process, and they want the story to make sense. This metaphor in fact forms the title to my book, Last Chapters: A Sociology of Aging and Dying (1980).

The above example shows that, while there were some kinds of data I could not gather through the survey, similarly, I could not gather some kinds of data through participant observation. I would have had to spend a great many more hours in the field than I was able to spend in order to observe enough reminiscence behaviour to be able to make sense of it. I was interested, moreover, in not only conversational, but personal or private reminiscence as well. I had to ask questions about that, and, like other investigators, I found that asking investigators to perform a reminiscence task which I could then code (and even quantify) along several dimensions, was helpful and indeed invaluable.

Whether through lack of imagination or a tendency to avoid deductive theorizing, I have discovered a tendency in myself to build an analysis from a striking observational feature. While the previous example included a survey research testing, in one other instance (Marshall, 1975b), the analysis remained qualitative. On my first days in the two research settings, I noted a contrast. In the home for the aged, the nuns were hanging Christmas decorations; whereas in the retirement village, residents sat at a table making their own decorations. This was an obvious contrast which would have been difficult to miss. However, it would not have readily emerged from survey research, unless I had anticipated institutional variability in the degree to which residents are allowed and encouraged to assume control over their own lives. As this was an organizational dimension not widely discussed in the literature at that time (a decade ago), I do not think it was only my personal carelessness which left me ready to be surprised by that contrast. In any case, the contrast became more vivid through observation, and led to one of the major analyses from my dissertation (Marshall, 1975b).

For good or ill then (and I think for good), almost all of the analyses which I have reported have been stimulated by the participant observation component of my research. Indeed, whole series of data I gathered on activity versus disengagement theory questions, and satisfaction with retirement community living questions, have been left under-analyzed and un-reported. And they will remain that way, because this confessional lifereview on my doctoral research hopefully concludes my intense involvement with that project ( 13 years is a very long time!). The point I would like to make is that I think I have had a few reasonably original ideas governing the analysis of my dissertation data, but I fear I would not have had very many at all were it not for the participant observation component.

In truth I can go even further and admit that my preferences for qualitative methods gave me my substantive topic. For a variety of reasons, I had become interested in what $I$ then called sociological processes analogous to psychological process of self-deception or rationalization. My interest was very general and theoretical; and with the need to select a doctoral dissertation topic, I decided to address these interests. At that time, however, partly because of my own fears as to my limited abilities with statistics, and partly because I somehow felt that qualitative methods were "better" than quantitative ones, I sat down one day to think of a research setting where I might do participant observation. I wanted a setting where it would be easy to find a lot of social deception. Sideshows and magic shows were rejected as too "trivial"; and I was left with studying people close to the time of their own death. This setting for conducting research was just that-a setting. I was interested in the aged only because I had a rudimentary theory that: 1) no one wants to die a failure; 2) objectively, even in terms of the objectives people set for themselves, most people do die with many goals unrealized; 3) yet few people seem to die in despair; 4) therefore, there must be intense processes of deception, probably including social deception, during that stage of life when people are near to death.

Such is fate, then (and I try to warn graduate students of this): for the past 13 years I have become increasingly committed as a gerontologist because I did not want to study general processes imminence of social deception in, say, a social psychology laboratory. Studying the ways in which older people come to 
terms with the imminence of death was, initially, only a convenient way to study social processes of deception.

\section{NAIVETE AS CHECK ON EXISTING THEORY}

I am allowing my audience to correctly conclude that I was very naive when I commenced my dissertation research. Indeed I was naive and somewhat unread in gerontology, and this gave me a great advantage in being able to form some of my own views, inducing patterns from my own data, before having to confront some theoretical views at odds with my data. This threw me into conflict with the views of Elizabeth Kübler-Ross, whose book on the course of dying (1969) came out only after I had gathered enough data to know that she was entirely wrong with respect to older people at least. I have outlined my differences with her stage theory elsewhere (Marshall, 1978;1980), and will only say here that by the time I read her claim that all people fear death, I had met enough older people who were exceptions to this claim, and seen the ways in which they collectively dealt with death, to be able to gather survey and participant observation data showing how people deal with death in a non-fearing manner. That is, I did not allow existing theory to narrow my focus.

To be clear on this, I am not arguing that we should abandone attempts to test existing theory; only that if we confine our efforts to theory testing we are likely to miss important and interesting phenomena.

\section{QUALITY CONTROL ON THE SURVEY}

I would like to briefly consider a more practical advantage of including participant observation in research. It is wise to have the participant observer or observers well lodged in a research setting before attempting to launch a survey. The effects of the survey can then be monitored, and continuing observation can focus some attention on reactive effects of the survey. The timing of survey components can also be enhanced. A non-trivial example was my discovery in the participant observation stage that I should not knock on resident's doors at certain times of the day, because of customary morning nap patterns. Nothing might be more likely to generate a refusal to be interviewed than to be summoned from a nap and be asked to participate in the survey.

When things were going wrong with the interviewing, or when they appeared to go wrong, I was able to retreat to the apartment of some friends, to discuss the problem. One couple in particular became my "docs," and I would be offered tea or sherry and the chance to relax in the privacy of their apartment. When a string of refusals to be interviewed occurred in one geographical area of the retirement village, they were able to account for this in terms of some characteristics of residents who live there. In general, although I have no way of testing this belief, I am convinced that one reason for my relatively high response rate in the survey was my continuing presence in the community and the friendships I formed there.

\section{CONCLUSION}

I have only indirectly argued for the values of the participant approach. My direct argument has been for its value in conjunction with other methods. Despite its common usage in anthropology, and despite a growing number of excellent and informative studies using the methodology, hostility toward participant observation remains. I have suggested a variety of ways in which participant observation can enhance the value of the more "respectable" methodology of survey research.

Most important to me, but perhaps less important for some, is that participant observation helps me to understand and interpret the data I obtain through the survey. If other audiences are more likely to believe my numbers than my verbatim quotations, the reverse is true for me; and if what I "know" to be the case from living in a research environment is not borne out by the numbers I am able to generate to describe that environment, I am more likely to believe my qualitative than quantitative data. Numbers, to my mind, are only an alternative language for describing reality, a language most useful for some purposes, less useful for others. 
I have relied on my personal research experiences, but many of the same arguments appear in more general discussion by Seiber (1973). Participant observation gives you more data than you would otherwise have, and inevitably gives you data concerning events which would not be tapped through a survey research approach. This is useful both as a prelude to surveys, in informing your survey instrument design, in interpreting survey data, and in supplementing it. While in a triangulation of multiple-method strategy it is best to have closure on any given issue through as many data-gathering methods as possible, it is better to have some data rather than none at all for relevant occurrences in your research setting; and participant observation is much more flexible than the survey in this regard.

I have confessed that most of my own theoretical ideas have been prompted by participant observation experiences instead of by survey research experiences. Perhaps this is inevitable given the reliance on induction in the former case and on deductive reasoning in the latter. There are dangers in this. approach. One ignores existing theory at peril; and while one might wish to maintain a freedom from theoretical prejudices at early stages of a research project, ignoring theory should never. be recommended as long-term advice. I believe, for example, that Gubrium's otherwise excellent monograph, Living and Dying at Murray Manor (1975) suffers in failing to ever address general theoretical issues. But my point is that theoretical issues in the literature can be addressed with greater freshness and originality on the basis of data gathered with a relatively open mind.

An additional benefit of including a participant observation component in gerontological research is the very practical provision of some kind of quality control on the survey. Mistakes in timing and administration of the survey can be reduced, or smoothed over; and there are very real benefits to be gained from the friendships formed in the course of the field work.

I have not focused on the disadvantages of using participant observation. Perhaps most important for studies of transitions over the life course is the problem of maintaining field workers in one project over a protracted period of time. The approach is therefore not as suitable for longitudinal as for cross-sectional research. Field research employing participant observation is also labor-intensive and therefore somewhat costly. The methodology is likely to be more obstrusive in studies of older people than of younger, since most participant observers, especially in a team project employing hired-hand researchers, will be quite young compared to the older people being studied. Participant observers cannot be everywhere at once, and therefore projects using this approach are of necessity more bounded or limited in social space than those using large-scale sample survey designs. Finally (although I am sure other disadvantages could be listed), to go back to my initial choice of dissertation topic, because of my commitment to the participant observation methodology, I deliberately chose to study the aged in congregate residential facilities, instead of free-living older people in ordinary communities; for in the latter case the method would not be as efficient due to the lesser frequency of interactive contact with older people in non-congregate communities. In short, not all situations are amenable to participant observational data-gathering, and there is as great a danger that the methodological tail can wag the substantive dog with this approach as with any other.

These limitations noted, I believe we are greatly in need of more participant observation research in social gerontology. This is partly because we need good data; but the thrust of my remarks leads me to say that, more importantly, we are in need of good ideas. The methodology of participant observation has great promise for generating new theory.

\section{FOOTNOTES}

1. This paper relies on work conducted with support from The Canadian Council and McMaster University, and was written while supported as a National Health Research Scientist by Health and Welfare Canada. It is a revision of a paper presented at the symposium workshop: Conceptual and Methodological Issues in the Study of Lives in Transition, 31 st Annual Scientific Meeting of Gerontological Society, Dallas,
Texas, November, 1978.

2. In sociology, a response has been the emergence of secondary journals such as Urban Life, Symbolic Interaction and Qualitative Sociology. 
It is my belief that the problem in the sociology of aging is largely one of lack of adequate manuscripts based on qualitative data, rather than a reluctance of editorial staff of journals such as Journal of Geron tology or Aging and Human Development to publish such material.

3. I present systematic guidelines for rigorous participant observation in a methodological appendix to a study conducted on acute care hospital wards (Rosenthal, Marshall, Macpherson and French, 1980. 141-149). For a discussion of some severe problems I had in a dif ferent field setting, studying the socialization of medical students, see Shaffir, Marshall and Hass (1980)

\section{REFERENCES}

Barton, Allen, and Lazarzfeld

1955 "Some Functions of Qualitative Analysis in Social Research" Frankfurter Beitrage Zur Soziologie, Band 1:321-361 (also B.M. Sociology Reprint No. 336).

Becker, Howard S.

1958 Problems of Inference and Proof in Participant Observation," American Sociological Review, 23 (December):652-650.

1970 "Field Work Evidence:, Ch. 3, pp. 39-62, in Howard S. Becker Sociological Work, Method and Substance. Chicago: Aldine.

Bengtson, Vern L., Cuellar, Jose B. and Ragan, Pauline K.

1977 "Stratum Contrasts and Similarities in Attitudes Towards Death," Journal of Gerontology, 32, No. 1 (January):76-88.

Blumer, Herbert

1969 "The Methodological Position of Symbolic Interactionism," Ch. 1, pp. 1-60, in Herbert Blumer, Symbolic Interactionism. Englewood Cliffs, New Jersey: Prentice Hall.

\section{Chappell, Neena L.}

1978 "Senility: Problems in Communication," pp. 65-88 in Jack Hass and Bill Shaffir (eds.) Shaping Identity in Canadian Society. Scarborough, Ontario: Prentice-Hall of Canada.

Denzin, Norman K.

1970 The Research Act. Chicago: Aldine.

Glaser, Barney and Strauss, Anselm

1967 The Discovery of Grounded Theory. Chicago: Aldine.

Gubrium, Jaber F.

1975 Living and Dying at Murray Manor. New York: St. Martin's Press.

Heeren, John W. and Poss, Barry, L.

1971 "Becoming a Reality Constructionist: An Unexplored Area of the Sociology of Sociology," The American Sociologist, 6, No. 2, (May):158-160.
Hochschild, Arlie R.

1973 The Unexpected Community. Englewood Cliffs, New Jersey: Prentice-Hall.

Junker, Buford $\mathrm{H}$.

1960 Field Work. Chicago: The University of Chicago Press.

Kiefer, Christie W.

1974 Changing Cultures, Changing Lives. San Francisco: Jossey-Bass. Kübler-Ross, Elizabeth

1969 On Death and Dying. New York: Macmillan.

Lofland, John

1971 Analyzing Social Settings. Belmont, California: Wadsworth. Marshall, Victor W.

1973 "Game-Analyzable Dilemmas in a Retirement Village: A Case Study," International Journal of Aging and Human Development, 4, No. 4, 285-291.

1974 "The Life Review as a Social Process." Paper presented at 27th Annual Meeting of Gerontological Society, Portland, Oregon.

1975a "Socialization for Impending Death in a Retirement Village," American Journal of Sociology, 80, No. 5 (March):1124-1144.

$1975 b$ "Organizational Features of Terminal Status Passage in Residential Facilities for the Aged," Urban Life, 4, No. 3 (October):349-368

1975c "Age and Awareness of Finitude in Developmental Gerontology," Omega 6, No. 2,0:113-129.

1978 "The Denial Concept in Canadian and American Death and Dying Research." Paper presented at the symposium, "Death and Dying in Different Cultures." XI International Congress of Gerontology, Tokyo, Japan. Abstracted in the Proceedings, p. 156.

1980 Last Chapters: A Sociology of Aging and Dying. Monterey: Brooks/Cole.

Marshall, Victor W, and Tindale, Joseph A.

1979 "Notes for a Radical Gerontology," International Journal of Aging in Human Development. 9, No. 2:163-175.

Matthews, Sarah H.

1975 "Old Women and Identify Maintenance: Outwitting the Grim Reaper," Urban Life 5, No. 3:339-348.

1979 The Social World of Old Women. Beverly Hills and London: Sage Publications.

McCall, George J. and Simmons, J.L. (eds.)

1969 Issues in Participant Observation: A Text and Reader. Reading, Mass.: Addison-Wesley. 
Mid-American Review of Sociology

Myerhoff, Barbara G.

1978 "A Symbol Perfected in Death: Continuity and Ritual in the Life and Death of an Elderly Jew," Ch. 5, pp. 163-202 in Barbara G. Myerhoff and Andrei Simic (eds.) Life's CareerAging, Beverly Hills and London: Sage Publications.

Rosenthal, Carolyn J., Victor W. Marshall, A.S. Macpherson and Susan

B. French

1980 Nurses, Patients and Families. New York: Springer and London: Croom Helm.

Ross, Jennie-Keith

1977 Old People, New Lives. Chicago: University of Chicago Press.

Schatzman, Leonard and Strauss, Anselm L.

1973 Field Research. Englewood Cliffs: New Jersey: Prentice-Hall.

Seiber, Sam D.

1973 "The Integration of Fieldwork and Survey Methods," American Journal of Sociology 78, No. 6 (May):1335-1359.

Shaffir, William, Victor W. Marshall and Jack Haas

1980 "Competing Commitments: Unanticipated Problems of Field Research," Qualitative Sociology 2 (No. 3):56-71.

Stephens, Joyce

1976 Loners, Losers, and Lovers. Seattle and London: University of Washington Press.

Tindale, Joseph A.

1980 "Identity Maintenance Processes of Old Poor Men," Ch. 9, pp. 88-94, in Victor W. Marshall (ed.), Aging In Canada: Social Perspectives. Toronto: Fitzhenry and Whiteside.

Webb, Eugene J., Campbell, Donald T., Richard D., and Sechrest, L.

1966 Unobtrusive Measures: Nonreactive Research in the Social Sciences. Chicago: Rand McNally.

\section{DEATH AND MENTALLY RETARDED PERSONS}

\author{
Daryl Evans \\ University of Kansas
}

Mid-American Review of Sociology, 1981, Vol. VI, No. 2:45-60

Special images associated with the concept of death are applied to people who are mentally retarded. The images reflect, and are reflected in, social attitudes which often lead to alienating experiences for retarded persons. These experiences and the special images and social attitudes which are their antecedents are discussed. Brief attention is given to the reversal of the normal loss-grief sequence associated with death as it relates to mentally handicapped persons. The material for this exploratory study was gathered through: 1) participant observation, 2) interview and guided conversation, and 3) literature review.

\section{MENTAL IMPAIRMENT: WHO CARES?}

Mentally retarded persons constitute a sizable, but largely unknown, minority in our society. While there is controversy about incidence figures, it is generally accepted by professionals in the field of mental retardation that approximately three percent of the total population of the United States is mentally retarded (Gearheart and Litton, 1975:1). Despite the demographic magnitude of this figure, the findings of one investigation indicated that a very low percentage (as little as one percent) of the general population possess accurate or relevant information regarding mental retardation (Gottwald, 1970).

Such a finding is noteworthy because the special problems and needs of mentally handicapped persons are becoming more conspicuous in America as its citizens begin to experience the consequences of the so-called normalization/deinstitutionalization movement. The process of normalizing retarded people is said to utilize, "means which are as culturally normative as possible in order to establish and/or maintain behaviors which 